\title{
A Retrospective Evaluation of Equine Cutaneous Lesions Diagnosed in Southern Brazil
}

\author{
Matheus Viezzer Bianchi', Gisele Silva Boos², Lauren Santos de Mello', Thainã Piccolo Vargas', \\ Luciana Sonne', David Driemeier' \& Saulo Petinatti Pavarini'
}

\begin{abstract}
Background: Cutaneous lesions in horses are common, accounting for approximately $50 \%$ of all neoplasms of this species, and can cause irritability, pruritus and predispose to secondary infections. Studies have provided information of frequency of cutaneous neoplasms in horses, but few included non-neoplastic lesions. The aim of this study is to identify the frequency of cutaneous lesions in horses diagnosed in Southern Brazil, through a retrospective study and identification of the anatomic location of the lesion, the breed, gender and age of the animals affected.

Materials, Methods \& Results: A retrospective study on skin lesions in horses using the database of the Veterinary Pathology Laboratory located in Southern Brazil was carried out from January 2000 to February 2013. Cases were searched for and selected by diagnosis, considering age, breed, gender, location and time of occurrence. The most common lesions included sarcoid, exuberant granulation tissue, squamous cell carcinoma (SCC), pythiosis, habronemiasis, melanoma, papillomatosis and Culicoides hypersensitivity. The most affected age range for sarcoid was animals from 1 to 5 years of age and for SCC was over 15 years of age. There was a positive association between sarcoid occurrence and being female and between SCC and habronemiasis and being male. Sarcoid, exuberant granulation tissue, pythiosis and habronemiasis most frequently involved the limbs, while SCC affected the urogenital and ocular systems and melanoma affected the tail. Pythiosis, habronemiasis, Culicoides hypersensitivity and nodular collagenolytic granuloma had seasonal occurrences. Sarcoid, exuberant granulation tissue and SCC were the most commonly diagnosed lesions. Sarcoid affected mostly younger animals, while SCC commonly affected older animals. Habronemiasis and Culicoides hypersensitivity occurred mostly during the spring and summer, while pythiosis most often presented during autumn and winter.

Discussion: The frequency of neoplastic lesions in the present work was similar to other studies. Among horse skin neoplasms, sarcoid is the most common, as was observed in this study. Sarcoid primarily affects young animals and most of these have an age range between one and five years, which was also noted and supported by statistical analysis. EGT is the most common non-neoplastic lesion in the skin of horses, most commonly in the limbs. The high frequency described may be related to a higher genetic predisposition or due to the employment of these horses in intensive work. SCC is the second most common skin neoplasm and often affects older horses, as it was observed. Urogenital tract and males were the most affected location and gender. Due to their ventral location, smegma may be a more likely etiology. It was observed a lower frequency of pythiosis and this may be due to the geographical location of the laboratory, where economy it is not based on livestock or rice farming, which can predispose animals to stay in stagnant water. Cutaneous habronemiasis is often diagnosed during warm months that have high biting insect activity, as observed here, where $75 \%$ of the cases occurred during the spring-summer. Differential diagnoses of nodular collagenolytic granuloma and habronemiasis was based not only on the presence of the parasite but also on the morphologic features of the lesion. Culicoides hypersensitivity is the most common and severe allergic condition in horses distributed worldwide because of the favorable weather conditions for the reproduction of the insect. In this study, $75 \%$ of the cases occurred during the spring-summer. Lesions are usually multiple, as it was observed in $50 \%$ of the cases.
\end{abstract}

Keywords: horses diseases, cutaneous lesions, neoplasm, tumour-like lesions, inflammatory lesions. 


\section{INTRODUCTION}

Cutaneous lesions are common and important in horses. After dogs and cats, horses are the third species most commonly affected by skin lesions. Skin diseases can cause annoyance, irritability, pruritus and secondary infections. Furthermore, they can compromise the comfort and appearance, interfere with the ability of the horse to perform and cause economic losses [12].

Many studies have provided information regarding the prevalence of cutaneous neoplasms in horses $[12,13,16]$, but few included non-neoplastic lesions [15]. Grossly, many of these are similar, and a definitive diagnosis is made through histopathology [15].

According to some studies, approximately 2-4\% of horses examined presented with skin lesions $[11,12]$. However, nearly $18 \%$ of horse samples submitted for histopathological examination are cutaneous neoplasms [4], making up to 50\% of all neoplasms [1]. Sarcoid, squamous cell carcinoma (SCC), melanoma and papilloma are frequently diagnosed $[12,13,15]$. Among non-neoplastic cutaneous lesions, the most common is exuberant granulation tissue, followed by nodular collagenolytic granuloma, pythiosis and habronemiasis $[13,15]$.

The aim of this study is to identify the frequency of cutaneous lesions in horses diagnosed in Southern Brazil, through a retrospective study of the database from January 2000 to February 2013 and to identify the anatomic location of the lesion, the breed, gender and age of the animals. In addition, we sought to determine the seasonality of these lesions and to evaluate via statistical methods if this was related to the rate of occurrence.

\section{MATERIALS AND METHODS}

A search in the database of anatomopathological examinations submitted to Veterinary Pathology Laboratory located in Southern Brazil, from January 2000 to February 2013 for the identification of skin lesions in horses was performed. Information from these reports, such as diagnosis, gender, age, breed, location and time of occurrence, was gathered and organized for subsequent data analysis. Equines were classified as male or female because the neuter status was not always specified. Age ranges included less than 1 year old, 1 to 5 years old, 6 to 14 years old and beyond 15 years old. Anatomic location of the lesions included limbs, urogenital tract, trunk, head, otic, ocular, neck, tail and multiple locations. Sometimes, localization of the skin lesions was not specified and classified as only skin. Two groups, including spring-summer and autumn-winter, were used to identify seasonality.

Statistical analysis of age range, gender and breed was performed with a chi-squared test and a significance value of 5\% using the Statistical Package for Social Science (SPSS), version 18.

\section{RESULTS}

From January 2000 to February 2013, the laboratory received 1,080 horse samples for anatomopathological examination, and 227 of these were from skin lesions $(21.01 \%)$. A diagnosis was reached in 224 cases: 133 were neoplastic lesions and 91 nonneoplastic lesions. The most prevalent neoplastic lesion was sarcoid, making up 33.48\% (76/227) of the cases, followed by SCC at $14.98 \%$ (34/227), melanoma at $4.41 \%$ (10/227) and papillomatosis at $3.52 \%(8 / 227)$. The most prevalent non-neoplastic lesion was exuberant granulation tissue (EGT), making up $17.18 \%$ of the cases $(39 / 227)$, followed by pythiosis at $5.73 \%$ $(13 / 227)$, habronemiasis at $5.29 \%(12 / 227)$, Culicoides hypersensitivity at $3.52 \%(8 / 227)$ and nodular collagenolytic granuloma (eosinophilic granuloma) at $1.76 \%$ (4/227). The prevalence of the skin lesions is shown in Table 1 .

Age was reported in $65.63 \%(149 / 227)$ of the cases, with a mean age of 8 years old for animals with neoplastic lesions (92 cases) and 8.1 years old for nonneoplastic lesions (57 cases). Age ranged from 0.5 to 25 years old. A chi-squared test was performed to determine the correlation between diagnosis and age. Thus, it was observed that sarcoid is more common between one to five years of age and SCC is more common at greater than 15 years of age. Prevalence of skin lesions according to age range is shown in Table 2.

Breed distribution of skin lesions was reported in $75.3 \%(171 / 227)$ of cases. The Criollo was the most affected breed, making up $52.04 \%(89 / 171)$ of the samples, followed by mixed breed at $30.4 \%(52 / 171)$, Mangalarga at $4.67 \%$ (8/171), Quarter horse at 3.5\% $(6 / 171)$ and Thoroughbred at 2.92\% (5/171). Based on chi-squared results, we found a correlation between sarcoid and the Criollo breed. 
Gender was registered in $81.05 \%$ (184/227) of the samples, in which females accounted for $54.9 \%(101 / 184)$ and males accounted for $45.1 \%$ (83/184). Based on chisquared results, we found a positive correlation between sarcoid occurrence and females and a positive correlation between SCC and habronemiasis and males.

The anatomic location of the lesion was listed for $72.68 \%$ (165/227) of the cases. Sarcoid presented multiple location, but it was more common on limbs (19/76), as it was exuberant granulation tissue (24/39); SCC presented mainly as an urogenital (20/34) and ocular (8/34) lesion. Pythiosis mostly affected the limbs (5/13) and head (3/13), while habronemiasis mostly occurred on limbs (5/12) and melanoma on the tail (5/10). Anatomic location of the lesions is shown in Table 3.
The seasonality of the lesions was evaluated, and it was observed that pythiosis, habronemiasis, Culicoides hypersensitivity and nodular collagenolytic granuloma (eosinophilic granuloma) showed evidences of seasonal occurrence. Approximately $69.23 \%$ (9/13) of the pythiosis cases occurred during autumn-winter, while habronemiasis, Culicoides hypersensitivity and nodular collagenolytic granuloma (eosinophilic granuloma) occurred mostly during spring-summer, making up $75 \%$ (9/12), $75 \%$ (6/8) and $100 \%$ (4/4) of cases, respectively.

The correlation between diagnosis and anatomic location, as well as the correlation between diagnosis and time of occurrence, was not analyzed due to the small number of cases in each group.

Table 1. Summary of horses skin lesions diagnosed in Southern Brazil.

\begin{tabular}{|c|c|c|c|c|c|}
\hline Lesion & Number & $\begin{array}{c}\% \text { of total skin } \\
\text { lesions }\end{array}$ & $\begin{array}{c}\% \text { of total horse } \\
\text { samples }\end{array}$ & $\begin{array}{c}\text { Mean age } \\
\text { (years) }\end{array}$ & $\begin{array}{c}\text { Age range } \\
\text { (years) }\end{array}$ \\
\hline Sarcoid & 76 & 33.48 & 7.04 & 5.7 & $0.5-18$ \\
\hline Exuberant granulation tissue & 39 & 17.18 & 3.61 & 7.7 & $2.5-24$ \\
\hline Squamous cell carcinoma & 34 & 14.98 & 3.15 & 13.9 & $6-24$ \\
\hline Pythiosis & 13 & 5.73 & 1.20 & 5.2 & $0.5-12$ \\
\hline Habronemiasis & 12 & 5.29 & 1.11 & 10.8 & $2-22$ \\
\hline Melanoma & 10 & 4.41 & 0.93 & 9.8 & $2-20$ \\
\hline Papillomatosis & 8 & 3.52 & 0.74 & 6.5 & $4-10$ \\
\hline Culicoides hypersensitivity & 8 & 3.52 & 0.74 & 11.8 & $5-25$ \\
\hline Pyogranulomatous dermatitis & 8 & 3.52 & 0.74 & 11.4 & $2-21$ \\
\hline Other neoplasms ${ }^{\mathrm{a}}$ & 5 & 2.2 & 0.46 & 10.8 & $7-20$ \\
\hline Nodular collagenolytic granuloma & 4 & 1.76 & 0.37 & 5.5 & $3-8$ \\
\hline Aural plaque & 3 & 1.32 & 0.28 & 3 & 3 \\
\hline Other infectious ${ }^{\mathrm{b}}$ & 3 & 1.32 & 0.28 & 5.7 & $3-8$ \\
\hline Collagenous hamartoma & 1 & 0.44 & 0.09 & 7 & 7 \\
\hline Inconclusive & 3 & 1.32 & 0.28 & N.I ${ }^{\mathrm{c}}$ & N.I ${ }^{\mathrm{c}}$ \\
\hline
\end{tabular}

${ }^{\mathrm{a} M a s t}$ cell tumor, lymphosarcoma, fibroma and hemangioma; ${ }^{\mathrm{b}}$ Phaeohyphomycosis caused by Curvularia sp., botryomycosis and cutaneous philariasis; cNot informed.

Table 2. Prevalence of horses skin lesions diagnosed in Southern Brazil according to age range.

\begin{tabular}{|c|c|c|c|c|c|}
\hline \multirow{2}{*}{ Lesion } & \multicolumn{5}{|c|}{ Age range } \\
\hline & $<1$ year & $1-5$ years & $6-14$ years & $>15$ years & N.I ${ }^{\mathrm{c}}$ \\
\hline Sarcoid & $3(3.95 \%)$ & $33(43.42 \%)$ & $19(25 \%)$ & $3(3.95 \%)$ & $18(23.68 \%)$ \\
\hline Exuberant granulation tissue & - & $8(20.51 \%)$ & $14(35.9 \%)$ & $2(5.13 \%)$ & $15(38.46 \%)$ \\
\hline Squamous cell carcinoma & - & - & $11(32.35 \%)$ & $9(26.47 \%)$ & $14(41.18 \%)$ \\
\hline Pythiosis & $3(23.08 \%)$ & - & $4(30.77 \%)$ & - & $6(46.15 \%)$ \\
\hline Habronemiasis & - & $3(25 \%)$ & $2(16.67 \%)$ & $3(25 \%)$ & $4(33.33 \%)$ \\
\hline Melanoma & - & $2(20 \%)$ & $2(20 \%)$ & $2(20 \%)$ & $4(40 \%)$ \\
\hline Papillomatosis & - & $1(12.5 \%)$ & $3(37.5 \%)$ & - & $4(50 \%)$ \\
\hline Culicoides hypersensitivity & - & $1(12.5 \%)$ & $3(37.5 \%)$ & $1(12.5 \%)$ & $3(37.5 \%)$ \\
\hline Pyogranulomatous dermatitis & - & $2(25 \%)$ & $1(12.5 \%)$ & $2(25 \%)$ & $3(37.5 \%)$ \\
\hline Other neoplasms ${ }^{\mathrm{a}}$ & - & - & $3(60 \%)$ & $1(20 \%)$ & $1(20 \%)$ \\
\hline Nodular collagenolytic granuloma & - & $1(25 \%)$ & $1(25 \%)$ & - & $2(50 \%)$ \\
\hline Aural plaque & - & $2(66.67 \%)$ & - & - & $1(33.33 \%)$ \\
\hline Other infectious ${ }^{\mathrm{b}}$ & - & $1(33.33 \%)$ & $2(66.67 \%)$ & - & - \\
\hline Collagenous hamartoma & - & - & $1(100 \%)$ & - & - \\
\hline Inconclusive & - & - & - & - & $3(100 \%)$ \\
\hline
\end{tabular}




\section{DISCUSSION}

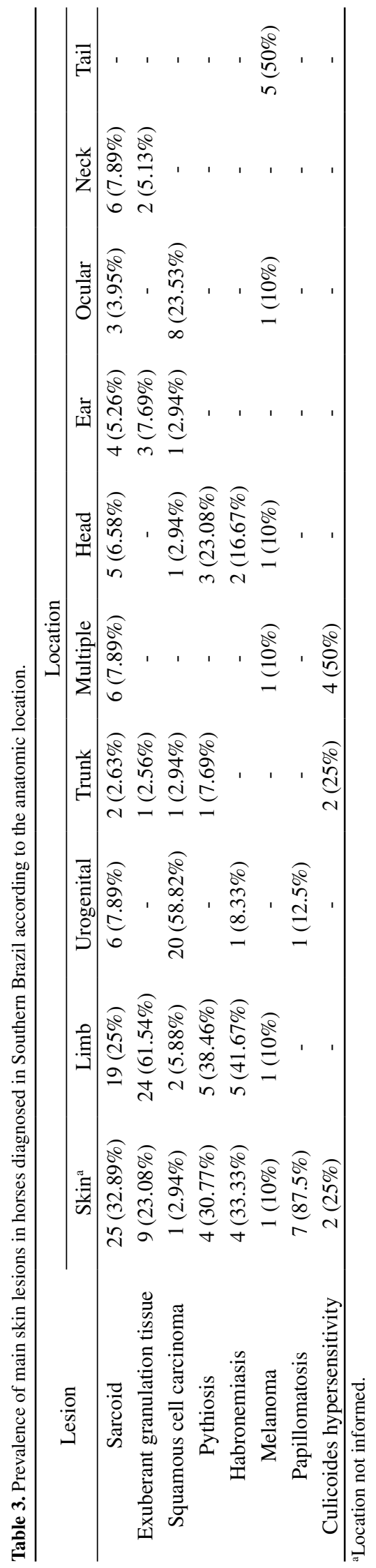

In the present work, $21.01 \%$ of the samples in the database were skin lesions, which is similar to what was described in a retrospective study of samples submitted to the diagnostic laboratory at Cornell University [12], where they found that $23.40 \%$ of the samples received from 1978 to 1994 were skin lesions.

The frequency of neoplastic lesions was also similar to other studies $[4,9,14]$. However, a work showed that $30 \%$ of all samples received were skin neoplasms [16], which is more than twice that observed in the present work. This can be explained by regional differences, such as local weather and breed popularity. Supporting this theory, in the same area as the previously mentioned work, it was found that approximately $18 \%$ of the equine cutaneous proliferative and nodular lesions were non-neoplastic [15], which is half of what was found here. Comparing both studies, we suggest that this difference occurred due to a higher frequency of EGT, pythiosis, habronemiasis and Culicoides hypersensitivity in the zone covered by our laboratory. These lesions may have a higher incidence due to regional influences, such as weather and the environment where the animals are bred.

Among horse skin neoplasms, sarcoid is the most common $[7,12,13,16]$, as was observed in this study. Sarcoid, compared to other skin neoplasms, primarily affects young animals [18], and most of these animals have an age range between one and five years [2]. This was also noted in the current study and supported by statistical analysis. The Criollo was the breed most affected by sarcoid. This breed is widely employed in Rio Grande do Sul for handling cattle herds, and the close contact with cattle may enhance the exposure of these horses to Bovine Papillomavirus $[12,13]$. Often there are multiple lesions [2,12], and in warmer weather, the limbs are the location most commonly affected by sarcoid [6,12], as was observed in this study. Furthermore, females were mainly affected, as it was described [2]. However, according to a study more geldings than mares or stallions were diagnosed with sarcoids, suggesting that castration surgery is a risk factor for the development of sarcoids [18].

EGT is the most common non-neoplastic lesion in the skin of horses, with a prevalence ranging from $6.5 \%$ to $8 \%[7,15]$. These lesions have usually failed to progress through the stages of healing, are trapped in the proliferative phase of repair [3] and are related 
to skin wounds or previous resection treatments [7]. EGT occurs most commonly in the limbs [3], as was observed in this study. The high frequency $(17.18 \%)$ described herein may be related to a higher genetic predisposition in the animals [3] or may be linked to the employment of these horses in intensive work, which easily leads to lesions and wounds. Non-neoplastic nodular lesions often occur in horses older than 10 years of age, with an average of 11 years of age for EGT [15]. Although the average age for EGT here was lower, most of the animals were 6 to 14 years old.

Some authors have found that SCC makes up $18.3 \%$ and $24.6 \%$ of the total number of neoplasms $[14,16]$, which is similar to our findings. Thus, this is the second most common cutaneous neoplasm of the horse [12]. When analyzing all skin lesions, the frequency is $14.98 \%$. This is slightly above what other authors have found [7,13], which was $11.65 \%$ and $10.2 \%$, respectively. SCC often affects older animals, with an average age of 15 years for skin lesions, 21 years for penile and preputial lesions and 19 years for vulvar, anal or perianal lesions [16]. In this study, the most affected age range was animals older than 14 years old, as described [13]. SCC is the most common urogenital tumor of the male horse and often occurs in older animals [17]. The irritant and carcinogenic properties of equine smegma have been implied as an etiology for SCC of the prepuce. However, at other locations, an increase in mean annual solar radiation and a decrease in skin pigmentation are listed as causes [12]. The greater frequency of SCC found in this study may be explained by increased sunlight exposure, especially in grazing horses [16]. However, the urogenital tract was the most commonly affected location and males were the most affected gender, and because of the decreased exposure of the external genitalia to sunlight due to their ventral location, smegma may be a more likely etiology.

In this study, we observed that $5.73 \%$ of the lesions were due to pythiosis. Some authors have reported a prevalence that ranges from $8.3 \%$ to $14 \%$ among skin biopsies $[5,13]$. This difference may be due to the geographical location of the laboratory. The economy around Porto Alegre is not based on farming, livestock, or rice farming, which can cause pythiosis when animals stay in stagnant water for long periods of time [5]. Lower body parts, such as the distal limbs and ventral abdomen, are more commonly affected by pythiosis because they are more susceptible to traumatic lesions and have more contact time with water [10]. In this study, we also observed a higher frequency of pythiosis on the limbs. Furthermore, we found that most of the cases occurred during the autumn-winter, and pythiosis samples are often received during this period [5]. However, the progression of the disease from the first observation until sampling is variable, and therefore, most of the infections likely occur during the warmer period of the year (spring-summer) due to the zoosporogenesis of the agent under these conditions.

Among the seasonal skin diseases of horses, habronemiasis, Culicoides hypersensitivity and nodular collagenolytic granuloma are common [12]. Cutaneous habronemiasis is often diagnosed during warm months that have high biting insect activity [15], as observed here, where $75 \%$ of the cases occurred during the spring-summer. Seasonal data analysis can be confusing due to the variable time between surgical excision and dispatch to the laboratory. Thus, some samples received during the autumn-winter may have been collected earlier, or the surgical procedure was delayed because of the weather or the competition schedule of the horse [15].

Habronemiasis lesions are most commonly seen on the legs, abdomen, prepuce, urethral process of the penis and medial canthus of the eyes, with no apparent age, breed or sex predilection [12]. However, in the current study, males were more commonly affected than females. Additionally, the high frequency of limb infection may be related to predisposing factors, such as chronic wetting or wounds [12]

There are reports of the prevalence of habronemiasis at $1.5 \%$ when nodular and proliferative lesions were analyzed [15]. In our study, however, it was observed that habronemiasis accounted for 5.29\% of the cases. In contrast, nodular collagenolytic granuloma had a frequency of approximately $1.76 \%$, which is lower than the reported 3.5\% [12,15]. Differential diagnoses of nodular collagenolytic granuloma and habronemiasis are often difficult when the parasite is not present on the examined slides [8]. This could explain the different conclusions of the reports because some of the cases diagnosed as nodular collagenolytic granuloma may indeed have been cutaneous habronemiasis. The diagnosis of habronemiasis in this study was based not only on the presence of the parasite but 
also on the morphologic features of the lesion even if the parasite could not be found at the site.

In a retrospective study at Cornell University over a 16-year period (1978-1994), melanoma was the second most common neoplasm in horses [12]. Yet some recent studies have found that this prevalence has decreased and is now at levels similar to those found in this study $[13,16]$. However, these data are based on biopsy submissions and most likely underestimate the actual prevalence of disease because clinicians rarely biopsy classical equine melanomas [12]. Melanomas occur most commonly in gray or white horses, especially Arabians and Percherons, with no sex predilection [12]. Most of the cases herein occurred on the tail, as described in the literature, where the lesions occur most commonly on the undersurface of the tail and in the perianal region [12]. The cause of melanoma is unknown, but it is thought to arise as a consequence of perturbed melanin metabolism. In humans, there is a correlation between exposure to ultraviolet light and the occurrence of melanoma. In horses, however, this does not seem to be an important factor, given that melanomas often occur in sun-protected areas [12].

Culicoides hypersensitivity is the most common and severe allergic condition in horses and is distributed worldwide because of the favorable weather conditions for the reproduction of the insect. Clinical evidence suggests that Culicoides hypersensitivity has a genetic predisposition but no breed, age or sex predilection [12]. In this study, $75 \%$ of the cases occurred during the spring-summer. A large proportion of the population of Culicoides spp. develops in the spring and reaches a peak in the summer, resulting in the seasonality of the disease [12]. Lesions are usually multiple, as it was observed in $50 \%$ of the cases, but, different insect species may have distinct preferential feeding sites, with the most common distributions being dorsal (pinna, mane, rump and base of tail) and ventral, with an occasional combination of locations [12].

\section{CONCLUSIONS}

Sarcoid, exuberant granulation tissue and SCC were the most commonly diagnosed lesions. Sarcoid affected mostly younger animals, while SCC commonly affected older animals and males. Habronemiasis and Culicoides hypersensitivity occurred mostly during the spring and summer, while pythiosis most often presented during autumn and winter.

Funding. This research was funded by CAPES and CNPq.

Declaration of interest. The authors report no conflicts of interest. All authors approved the manuscript and its submission to the journal.

\section{REFERENCES}

1 Baker J.R. \& Leyland A. 1975. Histological survey of the tumours of the horse, with particular reference to those of the skin. Veterinary Record. 96(19): 419-422.

2 Brum J.S., Souza T.M. \& Barros C.S.L. 2010. Aspectos epidemiológicos e distribuição anatômica das diferentes formas clínicas do sarcoide equino no Rio Grande do Sul: 40 casos. Pesquisa Veterinária Brasileira. 30(10): 839-843.

3 Celeste C.J., Deschene K., Riley C.B. \& Theoret C.L. 2011. Regional differences in wound oxygenation during normal healing in an equine model of cutaneous fibroproliferative disorder. Wound Repair and Regeneration. 19(1): 89-97.

4 Kerr K.M \& Alden C.L. 1974. Equine neoplasia - a ten year survey. Proceedings of American Association of Veterinary Laboratory Diagnosticians. 17: 183-187.

5 Marcolongo-Pereira C., Sallis E.S.V. \& Raffi M.B. 2012. Epidemiologia da pitiose equina na Região Sul do Rio Grande do Sul. Pesquisa Veterinária Brasileira. 32(9): 865-868.

6 Marti E., Lazary S., Antczak D.F. \& Gerber H. 1993. Report of the first international workshop on equine sarcoid. Equine Veterinary Journal. 25(5): 397-407.

7 Pascoe R.R. \& Summers P.M. 1981. Clinical survey of tumours and tumour-like lesions in horses in south east Queensland. Equine Veterinary Journal. 13(4): 235-239.

8 Pusterla N., Watson J.L., Wilson W.D., Affolter V.K. \& Spier S.J. 2003. Cutaneous and ocular habronemiasis in horses: 63 cases (1988-2002). Journal of the American Veterinary Medical Association. 222(7): 978-982.

9 Ramos A.T., Souza A.B., Norte D.M., Ferreira J.L.M \& Fernandes C.G. 2008. Tumores em animais de produção: aspectos comparativos. Ciência Rural. 38(1): 148-154. 
10 Sallis E.S.V., Pereira D.I.B. \& Raffi M.B. 2003. Pitiose cutânea em equinos: 14 casos. Ciência Rural. $33(5)$ : 899-903.

11 Scott D.W. 2007. Color atlas of farm animal dermatology. Ames: Blackwell, 252p.

12 Scott D.W. \& Miller W.H. 2003. Equine Dermatology. Philadelphia: Saunders, 823p.

13 Souza T.M., Brum J.S., Fighera R.A., Brass K.E. \& Barros C.S.L. 2011. Prevalência de tumores cutâneos de equinos diagnosticados no Laboratório de Patologia Veterinária da Universidade Federal de Santa Maria, Rio Grande do Sul. Pesquisa Veterinária Brasileira. 31(5): 379-382.

14 Sundberg J.P., Burnstein T., Page E.H., Kirkham W.W. \& Robinson F.R. 1977. Neoplasms of Equidae. Journal of the American Veterinary Medical Association. 170(2): 150-152.

15 Valentine B.A. 2005. Equine cutaneous non-neoplastic nodular and proliferative lesions in the Pacific Northwest. Veterinary Dermatology. 16(6): 425-428.

16 Valentine B.A. 2006. Survey of equine cutaneous neoplasia in the Pacific Northwest. Journal of Veterinary Diagnostic Investigation. 18(1): 123-126.

17 Van Den Top J.G.B., Emsink J.M., Gröne A., Klein W.R., Barnevald A. \& Van Weeren P.R. 2010. Penile and preputial tumours in the horse: literature review and proposal of a standardized approach. Equine Veterinary Journal. 42(8): 746-757.

18 Wobeser B.K., Davies J.L., Hill J.E., Jackson M.L., Kidney B.A., Townsend H.G.G \& Allen A.L. 2010. Epidemiology of equine sarcoids in horses in western Canada. Canadian Veterinary Journal. 51(10): 1103-1108. 